\title{
Micro-Scale Thermal Imaging of Organic and Polymeric Materials with Cooled and Uncooled Infrared Cameras
}

\author{
J. Morikawa, ${ }^{1}$ E. Hayakawa, ${ }^{2}$ and T. Hashimoto ${ }^{1}$ \\ ${ }^{1}$ Tokyo Institute of Technology, 2-12-1, S8-29, Ookayama, Meguro-ku, Tokyo 152-8550, Japan \\ 2 ai-Phase Co., Ltd., 2-15-19, Kami-osaki, Shinagawa-ku, Tokyo 141-0021, Japan
}

Correspondence should be addressed to J. Morikawa, morikawa.j.aa@m.titech.ac.jp

Received 10 August 2012; Revised 19 November 2012; Accepted 22 November 2012

Academic Editor: Antoni Rogalski

Copyright (C) 2012 J. Morikawa et al. This is an open access article distributed under the Creative Commons Attribution License, which permits unrestricted use, distribution, and reproduction in any medium, provided the original work is properly cited.

\begin{abstract}
The emissivity corrected thermal imaging combined with a real-time direct imposed-signal system on the freezing of biological cells is presented, which makes it possible to visualize the exothermic latent heat at a minus temperature. The applicability of the uncooled micro bolometer (thermal detector) to the micro-scale thermal analysis on the phase transitions of organic and polymeric materials is discussed in comparison with the photon detector, equipped with the optics originally designed.
\end{abstract}

\section{Introduction}

Noncontact thermal imaging methods are preferred in the characterization of materials in the increasing number of applications. Creating and monitoring thermal distributions with a spatial resolution of $\sim 10 \mu \mathrm{m}$ is required, in particular, for the materials developed in the energy saving and renewable technology [1].

A recent advance in IR detectors arrays provides the enhanced applications [2]. Thermal imaging applied to the materials' characterization in a micro-scale is summarized with actual imaging results of organic, polymeric, and biological materials, using a cooled and an un-cooled infrared cameras equipped with the optics originally designed in this study. Examples of microscale thermal analysis and the lockin thermography are presented. The latent heat generation and dissipation at minus temperatures during the freezing of biological cells are visualized that clarifies the thermal diffusion effect on crystallization and the vitrification [37]. On-lamellae thermal analysis of $n$-alkane visualizes the early stage of anisotropic lamella formation and the difference of thermal propagation in crystallizations and the rotator phase transitions [8]. The crystallization front of polymeric spherulite of poly(ethylene oxide) visualizes the temperature rise of $\sim 100 \mathrm{mK}$ [9]. The basic results of lockin thermography visualize the phase and amplitude image using a method of modulated spot heating with a diode laser that generates a thermal wave inside the specimen $[10,11]$.
A promising application of micro-bolometer sensor is additionally introduced [12].

\section{Approach and Techniques}

In order to visualize the material's thermal phenomena with a spatial resolution $\sim 10 \mu \mathrm{m}$ and in a time scale $\sim 10 \mathrm{~ms}$, the following techniques have been developed. The measurement is done preferably under the dynamic temperature field such as a constant rate heating/cooling and a temperature modulation.

2.1. Optics. Materials for optics suitable to the mid- and long-wave infrared cameras are chosen, respectively. Spatial resolutions $4.3 \mu \mathrm{m}$ (calculated at $\lambda=5 \mu \mathrm{m}, \lambda$ : wavelength) and $11.1 \mu \mathrm{m}$ (at $\lambda=10 \mu \mathrm{m}$ ) have been achieved for the indium antimonide ( $\mathrm{InSb}$ ) and vanadium oxide ( $\mathrm{VOx}$ ) detectors of focal plane arrays (FPAs), in a good balance of modulation transfer function (MTF) and numerical aperture (NA).

2.2. Precision Temperature Control. Equipped with the microlens, the measuring area is $1 \mathrm{~mm}^{2}$. Temperature control of the micro-scale area of the baseplate of a sample holder is required. The temperature is controlled with a precision of $0.1 \mathrm{~K}$ and a temperature scan at a constant rate of $0.1 \mathrm{~K}-$ $500 \mathrm{~K} / \mathrm{min}$ is routinely used. Together with the microalignment of an $x y z$ stage the temperature is controlled using a field programmable gate arrays (FPGAs). 


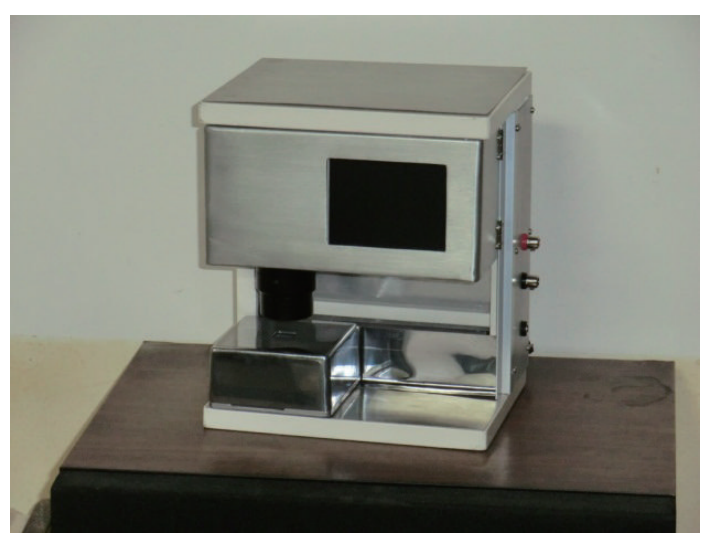

(a)

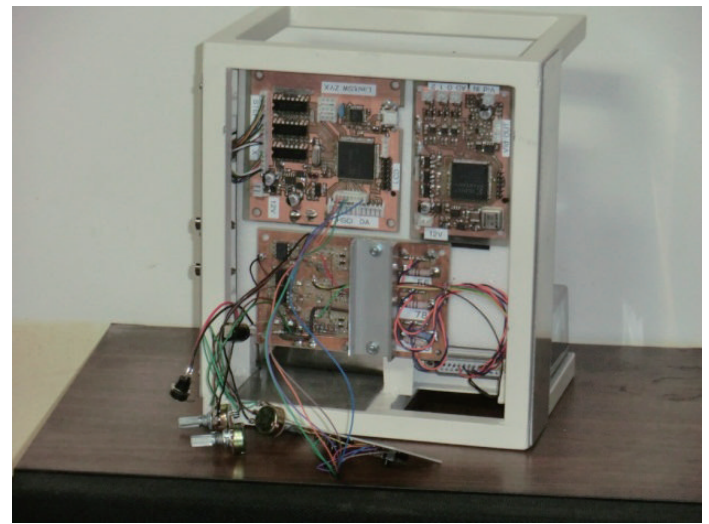

(c)

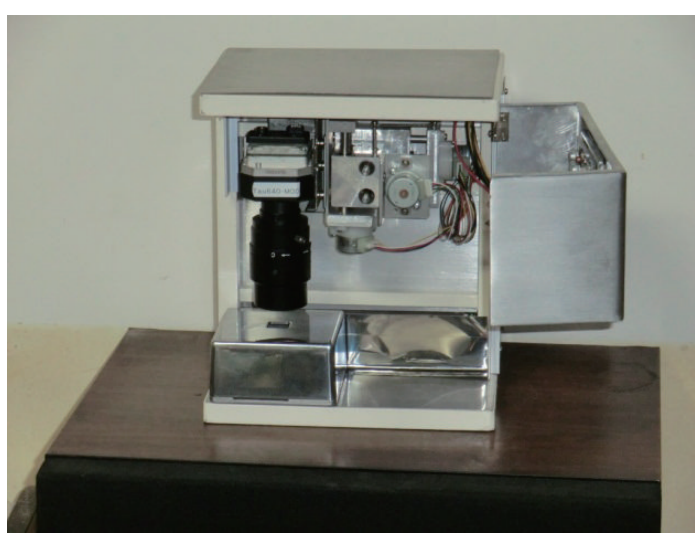

(b)

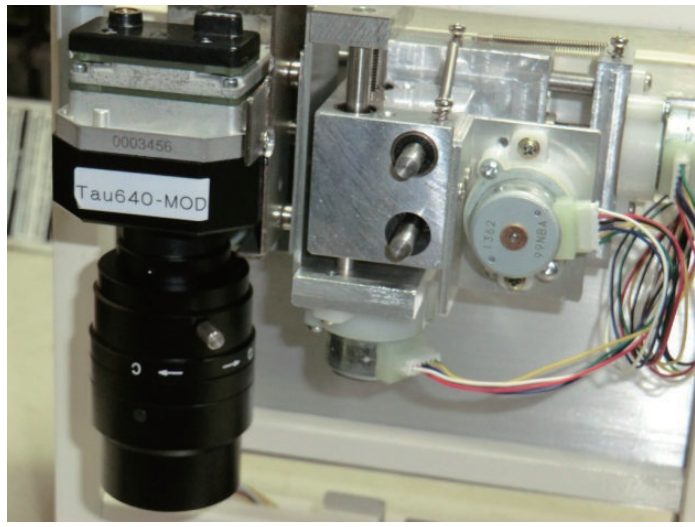

(d)

FIGURE 1: Photographical view of the experimental setup of a real-time direct signal imposing system with un-cooled IR FPA sensors equipped with a micro lens optical system. The hight of the instrument system box is $20 \mathrm{~cm}$.

2.3. Modulated Laser Scanning System. The excitation source was a laser diode (LD) of $0.1 \mathrm{~W}$ power emitting at $630 \mathrm{~nm}$ wavelength. The optical pick-up head was used to deliver light to inside/onto the sample by a PMMA lens of $D=4 \mathrm{~mm}$ diameter and $f$-number $=1.0$. The corresponding numerical aperture was $\mathrm{NA}=0.5$ and the focal spot size on the sample is estimated to be $d=1.22 \lambda / \mathrm{NA} \sim 1.5 \mu \mathrm{m}$. This is the size of a heat source.

2.4. Phase Lock-In Algorithm. It is based on the discrete cosine transform (DCT) and the inverse discrete cosine transform (IDCT). The heat source point is set as a reference point for the phase shift calculation.

2.5. Time Differential Images. It is calculated as a standard procedure as $I^{\prime}(t)=\partial I / \partial t=\min _{\Delta t \rightarrow 0}(I(t)-I(t-\Delta t)) / \Delta t$, where $I(t)$ is the intensity at a time moment $t$ and $\Delta t$ is a time interval between the captured images.

2.6. Inverse Processing. The method to estimate the local thermal diffusivity and a heat source distribution has been developed by Pradere et al. [7]. Considering the Laplacian terms, it enables to estimate the localized heat source and thermal diffusivity simultaneously.
2.7. Superimpose for the Emissivity Corrections. In spite of the improvement of the resolution of time and space with the techniques developed as above, the procedure for emissivity correction is still important, especially for the thermal phenomena including phase transitions. The emissivity change during phase transitions is not a simple function of temperature.

In order to calibrate the intensity of all pixels in FPA into temperature, the measured temperature data is directly imposed to the IR intensity signal [12]. The application of this approach to calibrate the emissivity into the temperature during the materials characterization is one of the purposes of this paper.

\section{Experimental}

The measuring instrument, including the signal imposing system, is designed as follows [12]:

A: signal (composite video signal) capturing part,

B: superimposer of video signal,

$\mathrm{C}$ : timing trigger generator,

D: synchronous IR camera with InSb or VOx FPA sensors, 


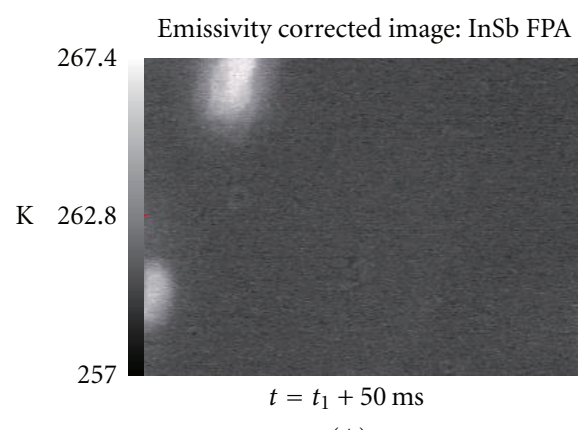

(A)

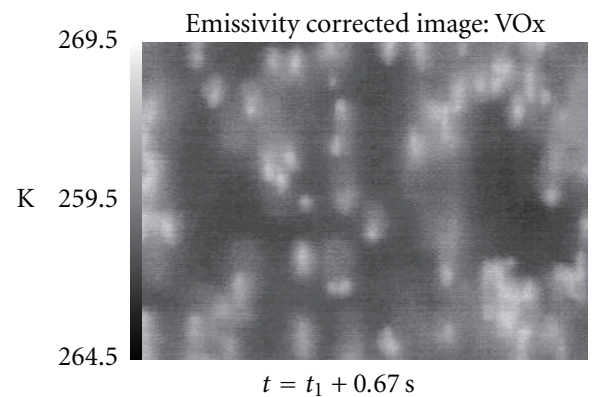

(a)

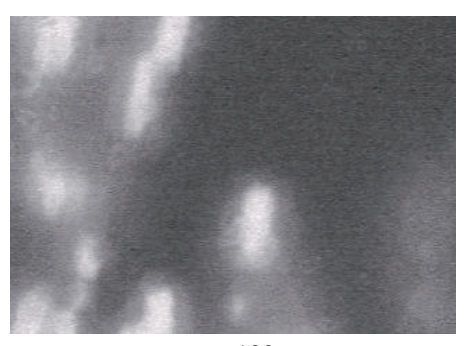

$t=t_{1}+133 \mathrm{~ms}$

(B)

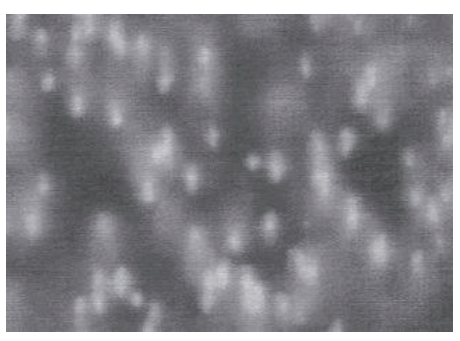

$t=t_{1}+0.77 \mathrm{~s}$

(b)

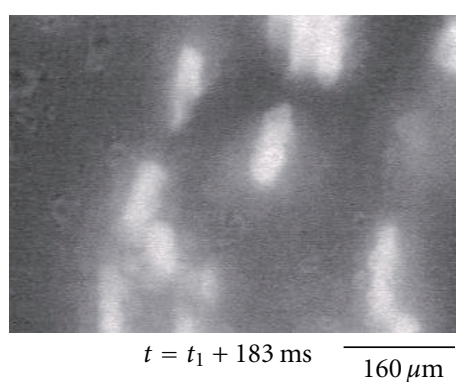

(C)

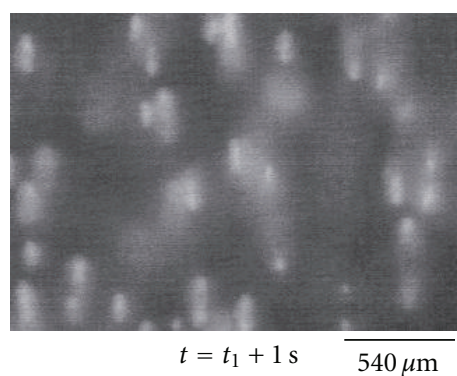

(c)

Figure 2: ((A),(B), and (C)) Sequence of the emissivity corrected image of freezing onion-skin cells at minus temperatures under a cooling scan observed with the InSb IR FPA $(30 \mu \mathrm{m}$ detector pitch) equipped with a $\times 7.5$ magnification micro lens. ((a), (b), and (c)) Sequence of the emissivity corrected image of freezing leek cells ((a),(b),(c)) at minus temperatures under a cooling scan $0.2 \mathrm{~K} / \mathrm{s}$ observed with the VOx IR FPA ( $17 \mu \mathrm{m}$ detector pitch) equipped with a $\times 2.5$ magnification micro lens. After the emissivity correction, temperature of each pixel is calibrated. The temperature is shown in the concentration bar in the left. The signal is captured via NTSC in the time interval as shown in the figures.

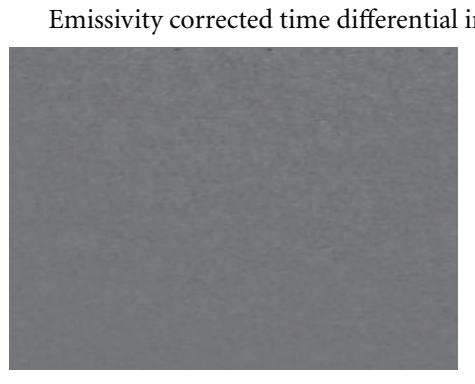

(a2)

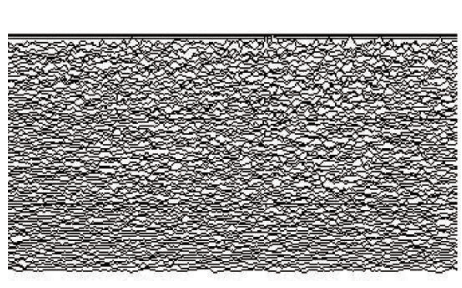

$t=t$

(a3)

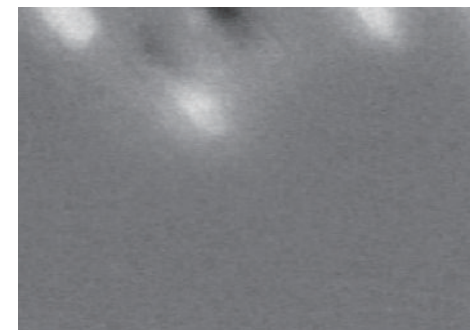

(b2)

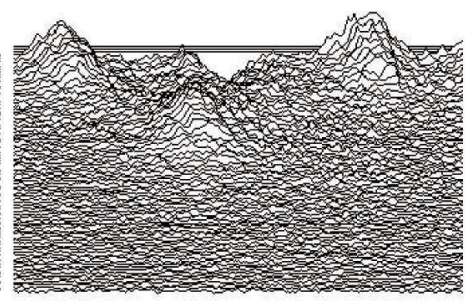

$t=t_{1}+3.45 \mathrm{~s}$

(b3)

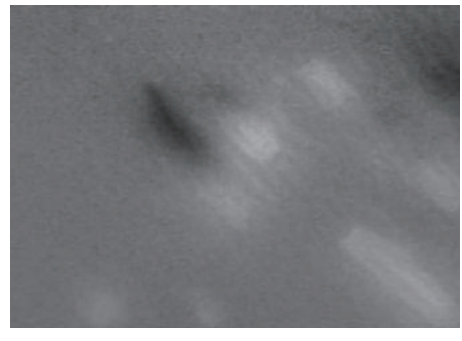

(c2)

$\overline{160 \mu \mathrm{m}}$

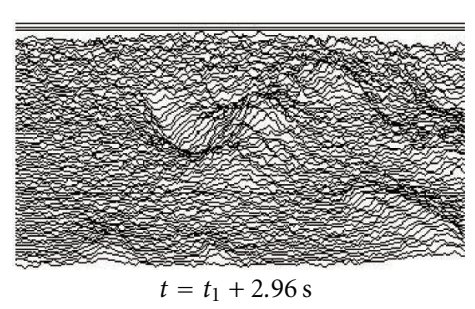

(c3)

FIgure 3: ((a2), (b2), and (c2)) Sequence of the time derivative thermal image of freezing biological cells captured with InSb IR FPA at minus temperatures and ((a3), (b3), and (c3)) the three-dimensional plot of time derivative image of (a2), (b2), and (c2). 


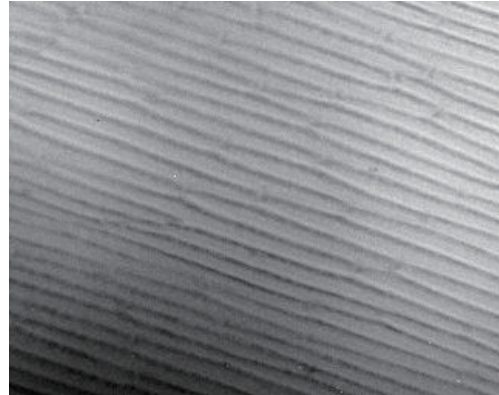

(a)

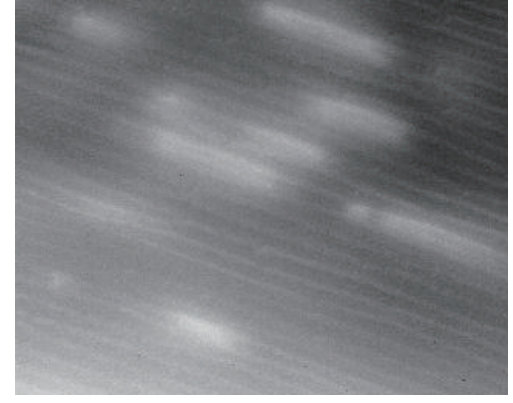

(b)

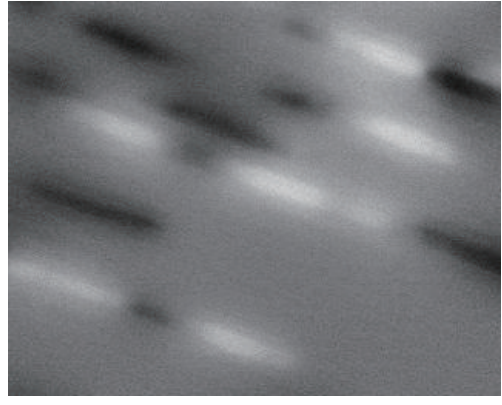

(c) $\overline{160 \mu \mathrm{m}}$

FIGURE 4: Thermal image of the freezing process of the cellular tissue of a leek observed with the InSb IR FPA equipped with a $\times 7.5$ magnifications micro lens. (a) The subtracted image, (b) the raw image, and (c) the temporal derivative image at minus temperatures.

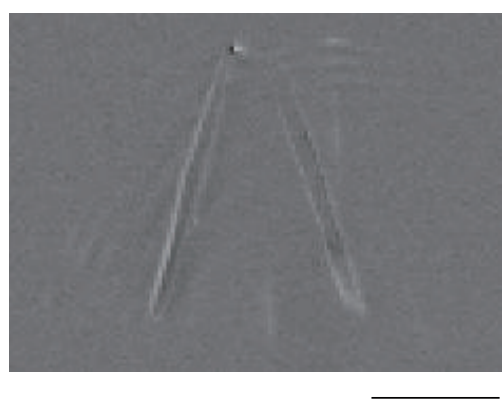

(a)

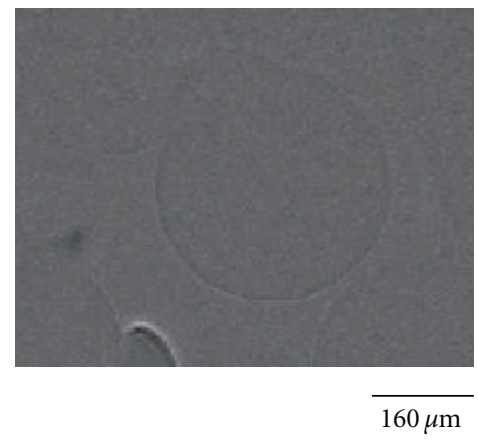

(b)

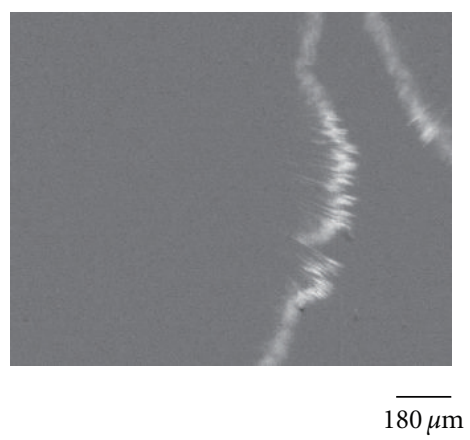

(c)

FIgURE 5: Thermal image in the crystallization of organic and polymeric materials; (a) $n$-pentacosane, $\mathrm{C}_{25} \mathrm{H}_{52}$, cooling at a rate of $0.6 \mathrm{~K} / \mathrm{min}$ from $56.1^{\circ} \mathrm{C}$ to $55.8^{\circ} \mathrm{C}$, (b) poly(ethylene oxide) at a cooling rate of $30 \mathrm{~K} / \mathrm{min}$ from the molten state, and (c) stearic acid at a cooling rate of $10 \mathrm{~K} / \mathrm{min}$ from the liquid state. The temporal derivative images are shown.

E: high-precision/high-speed temperature controller,

F: actuator and laser drive,

G: stage scanners.

A handy size design is realized when VOx FPA is applied. The photographical view of the instrument is depicted in Figure 1.

The laser drive for generating a modulated spot heating with $630 \mathrm{~nm}$ diode laser and the $x y$ positioning actuator are triggered with a timing signal synchronous to the video signal capturing. The video signal synthesizer makes it possible to record a direct signal of temperature or positioning data, simultaneously, with the imaging video signals. The imposed data are applied to the pixel emissivity corrections at one time under heating/cooling temperature scan. The Peltiertype dual heater is set to operate a heating and cooling scan of the specimens.

\section{Results}

4.1. Pixel by Pixel Temperature Calibration with the Imposed Temperature Signal. Figure 2 shows the thermal imaging of the biological tissues of onion-skin cells and leek cells in a cooling scan with the method of pixel by pixel temperature calibration with the imposed temperature signal. The emissivity is corrected with the imposed signal, and the calibrated temperature is shown as a contrast of light and shade. Shortly after the surface water becomes frozen, the freezing of cell starts in one cell by one cell, and because of the localized temperature rise caused by thermal diffusion from the freezing cell next to another one, the freezing proceeds in a random way.

Figure 3 shows the temporal derivative image of the freezing onion-skin cells using the emissivity corrected intensity. The white and dark color corresponds to the positive and the negative temporal derivative coefficient of temperature. The adjacent cells do not freeze continuously. This is a characteristic phenomenon in the freezing process in tissues of plant cells. The cell wall plays an important role in the transfer of the excited heat.

Comparing the temporal derivative images calculated from the emissivity corrected and uncorrected images, no large differences are found. However, the Laplacian terms are influenced by the emissivity correction procedure. This is promising to diminish the measuring noise that affects the inverse processing.

4.2. Crystallization of Organic and Polymeric Materials. Typical examples of the crystallization front of organic materials are shown in Figures 4 and 5. The anisotropic propagation of 


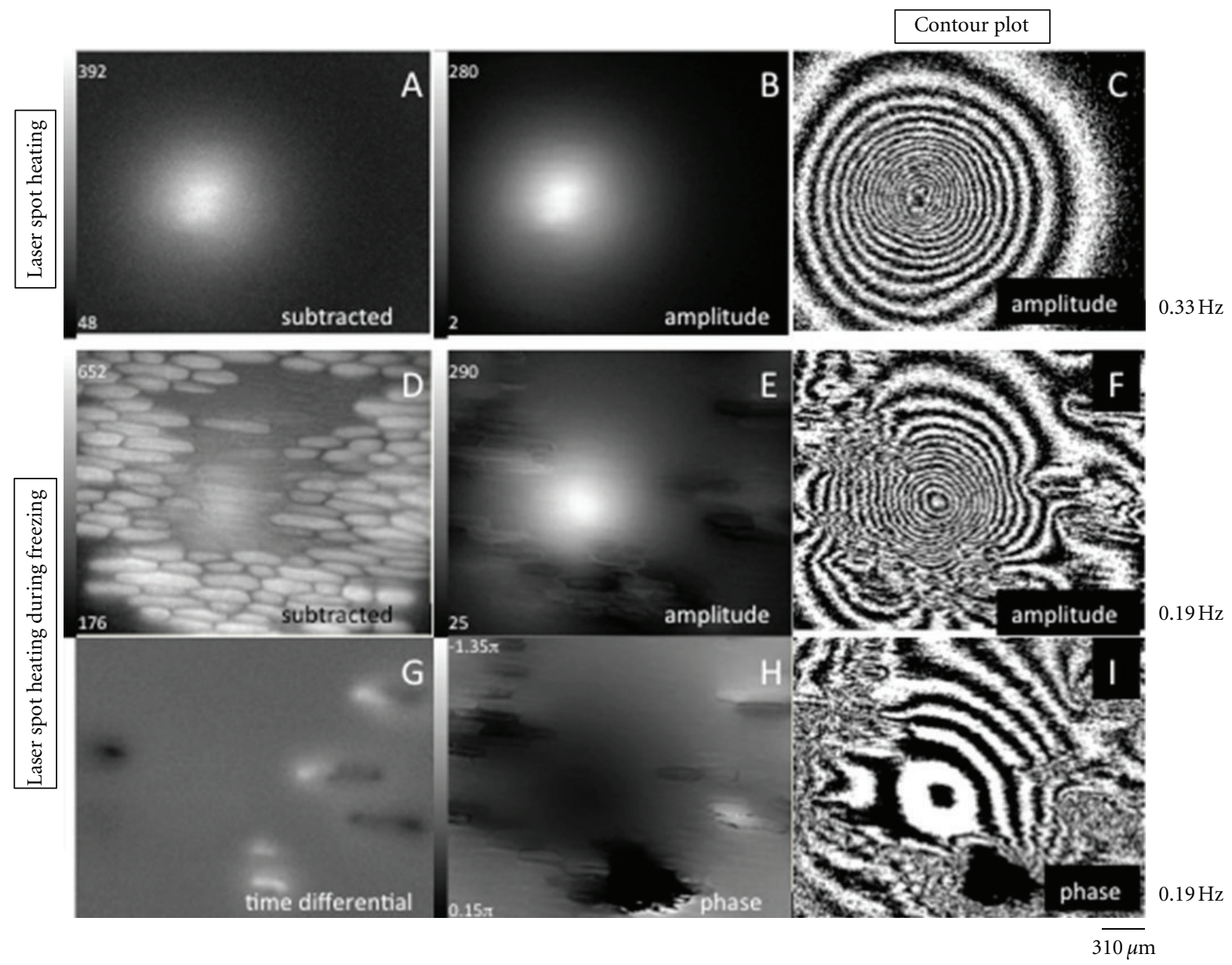

FIGURE 6: Phase-locked image in comparison with the subtracted image of onion-skin cells irradiated with a laser-modulated spot heating at r.t. ((A)-(C); $0.33 \mathrm{~Hz}$ ) and under a cooling temperature control ((D)-(I); $0.19 \mathrm{~Hz})$. A: subtracted image, B: amplitude image, (C): contour plot of (B), (D): subtracted image, (E): amplitude image, (F): contour plot of (E), (G): time differential image, (H): phase image, and (I): contour plot of $(\mathrm{H})$. observed with the InSb IR FPA $(25 \mu \mathrm{m}$ detector pitch $)$ equipped with a $\times 8.3$ magnification micro lens.

excited heat generated in the phase change strongly correlates to the high structure of the materials. In the tissue of leek (Figure 4), in spite of the twice longer cell size, the freezing occurs one cell by one cell.

The excited heat in the different crystal morphology, a linear shape, a spherulite, and a radial pattern are found in Figure 5, respectively. The bidirectional anisotropic heat propagation is observed in the crystallization of $n$-alkane. The emissivity correction before and after the phase change is important when thermal propagation is precisely extracted from the data.

\subsection{Application of the Phase Lock-In Technique}

4.3.1. The Effect of Noncontact Laser-Modulated Spot Heating during the Freezing of Onion-Skin Cells. Figure 6 shows the phase and amplitude image of onion-skin cells irradiated with a laser-modulated spot heating under a temperature control, kept at a room temperature (Figures 6(A)-6(C)) or cooled at a constant rate (Figures 6(D)-6(I)).

The bright-colored cells in the subtracted image of Figure 6(D) indicate that it has been frozen under cooling, with a simultaneous irradiation of a laser spot heating. The exothermic heat disturbs the modulated temperature field and the contour lines in the amplitude and phase image of Figures 6(F) and 6(I) are distorted in comparison with the contour image in Figure 6(C), where no exothermic heat is generated. The image in Figure 6 is captured with an InSb FPAs equipped with a micro lens.

A micro-scale laser-modulated spot heating is also captured with the uncooled IR camera systems (VOx FPAs) equipped with a micro lens. Figure 7 shows the examples of phase and amplitude thermal image of the polyimide film base copper clads laminates for flexible printed wiring boards scanned with a modulated laser irradiation.

The regular intervals of the contour lines in the phase image in Figures 7(B) and 7(C) indicate the homogeneous in-plane thermal diffusivity on the polyimide film region. On the other hand, if the spot heating is scanned between the copper wiring area (Figure 7(D)), the intervals of the phase contour lines become denser because of the higher and anisotropic thermal diffusivity of the copper leads area (Figure $7(\mathrm{E})$ ). The higher the frequency is, thermal wave 

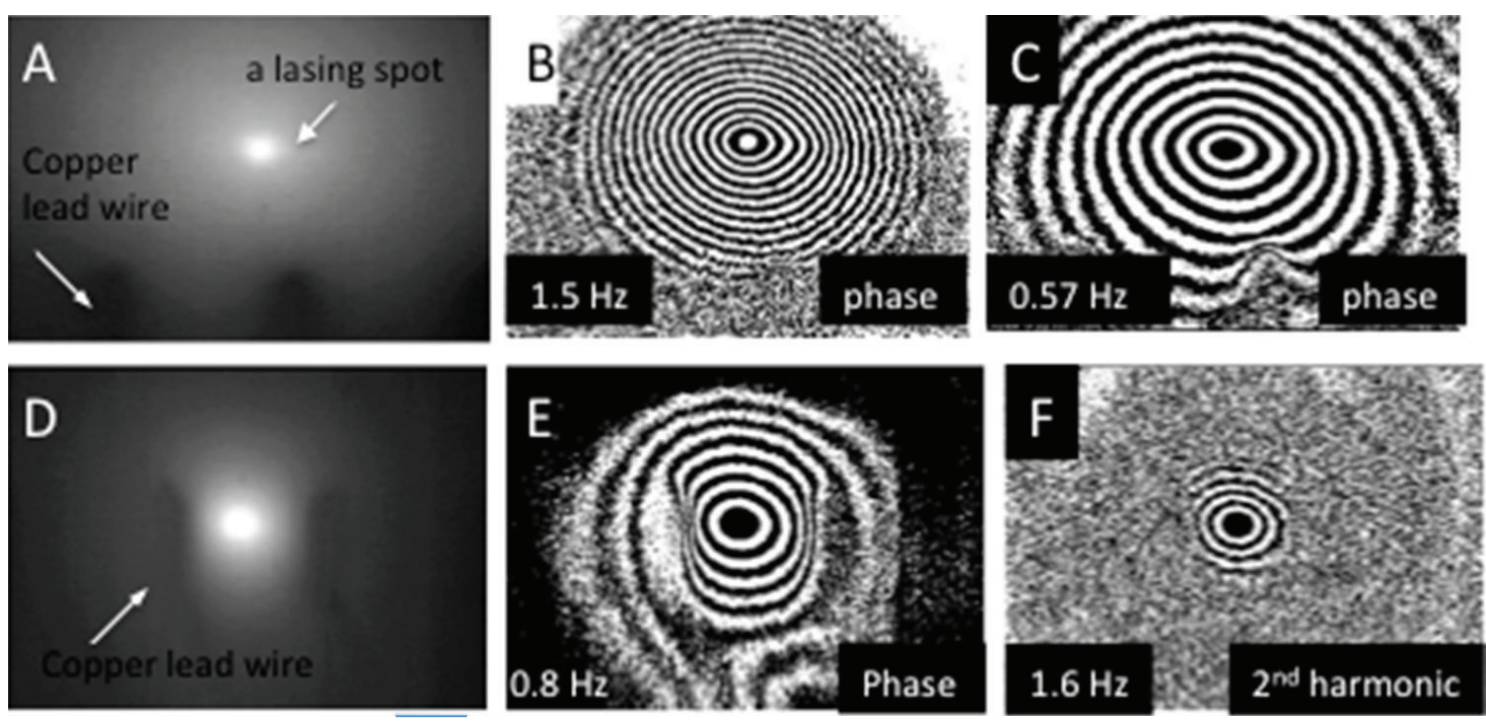

$500 \mu \mathrm{m}$

FIGURE 7: Phase-locked image with a contour line ((B), (C), (E), and (F)) in comparison with the raw image ((A), (D)) of the polyimide film base copper clads laminates for flexible printed wiring boards. The modulated frequencies are (B): $1.5 \mathrm{~Hz},(\mathrm{C}): 0.57 \mathrm{~Hz},(\mathrm{E}): 0.8 \mathrm{~Hz}$, and $(\mathrm{F})$ : $1.6 \mathrm{~Hz}$ (2nd harmonic image of (E)), observed with the VOx IR FPA ( $25 \mu \mathrm{m}$ detector pitch) equipped with a $\times 2.5$ magnification micro lens.

diminishes inside the wiring area and does not expand in the whole area of the film. The results in Figure 7 indicate the applicability of the micro-bolometer systems combined with the phase lock-in technique for the in-plane thermal characterization of the composite film.

\section{Conclusion}

The emissivity correction procedure and the phase-locked analysis are examined for the materials' thermal characterization both with the photon type and the thermal type IR detectors using the originally developed measuring systems. It will be of use to apply these results to mathematical processing to analyze the micro-scale thermal phenomena in order to develop the advanced materials.

\section{Acknowledgment}

Support via a Grant from Japan Science and Technology Agency (Development of System and Technology for Advanced Measurement and Analysis) is gratefully acknowledged.

\section{References}

[1] O. Breitenstein, J. Bauer, K. Bothe et al., "Understanding junction breakdown in multicrystalline solar cells," Journal of Applied Physics, vol. 109, no. 7, Article ID 071101, 10 pages, 2011.

[2] A. Rogalski, J. Antoszewski, and L. Faraone, "Third-generation infrared photodetector arrays," Journal of Applied Physics, vol. 105, no. 9, Article ID 091101, 44 pages, 2009.

[3] T. Hashimoto and J. Morikawa, "Two-dimensional microscale thermal analysis of freezing of onionskin cells by high-speed infrared focal plane arrays," Japanese Journal of Applied Physics, vol. 42, no. 6, pp. L706-L708, 2003.

[4] J. Morikawa, T. Hashimoto, E. Hayakawa, and H. Uemura, "Two-dimensional thermal analysis for freezing of plant and animal cells by high-speed microscopic IR camera," in Thermosense XXV, vol. 5073 of Proceedings of SPIE, pp. 148153, April 2003.

[5] J. Morikawa, T. Hashimoto, K. Yamamoto, and J. Ando, "Twodimensional thermal analysis for freezing of endothelial cells by high-speed microscopic IR focal plane arrays," in 6th Conference on Biomedical Thermosacoustics, Optoacoustics, and Acousto-Optics - Photons Plus Ultrasound: Imaging and Sensing, Proceedings of SPIE, pp. 282-290, January 2005.

[6] J. Morikawa, T. Hshimoto, and T. Eto, "Two-dimensional thermal analysis of organic materials by IR thermography," in Proceedings of the International Conference on Quantitative InfraRed Thermography (QIRT '06), Padva, Italy, June 2006, Paper no. 2006-036.

[7] C. Pradere, J. Morikawa, J. C. Batsale, and T. Hashimoto, "Microscale thermography of freezing biological cells in view of cryopreservation," Quantitative Infra Red Thermography Journal, vol. 6, no. 1, p. 37, 2009.

[8] J. Morikawa, T. Hshimoto, E. Hayakawa, and T. Eto, “Twodimensional thermal analysis of organic materials by microscale thermography," in International Conference on Quantitative InfraRed Thermography (QIRT '08), Krakov, Poland, July 2008.

[9] J. Morikawa, E. Hayakawa, K. Ikuo, and T. Hashimoto, “Twodimensional thermal analysis of organic molecular crystals and polymeric spherulites by microscale thermography," in Thermosense XXXII, vol. 7661 of Proceedings of SPIE, pp. 1-9, April 2010.

[10] J. Morikawa, T. Hshimoto, E. Hayakawa, T. Eto, and R. Li Voti, "Thermal characterization of multi-layer polymer film by IR thermography," in International Conference on Quantitative InfraRed Thermography (QIRT '08), Padva, Italy, June 2006, Paper no. 2006-020. 
[11] J. Morikawa, E. Hayakawa, and T. Hshimoto, "Thermal wave in a pulsed laser scanning system observed by a micro-scale thermography," in Proceedings of the 1st Meditterranean International Workshop on Photoacoustic \& Photothermal Phenomena, Erice, Italy, July 2010.

[12] J. Morikawa, E. Hayakawa, and T. Hashimoto, "Application of micro-scale thermography to the thermal analysis of polymeric and organic materials," in Thermosense: Thermal Infrared Applications XXXIII, vol. 8013 of Proceedings of SPIE, pp. 1-6, April 2011. 

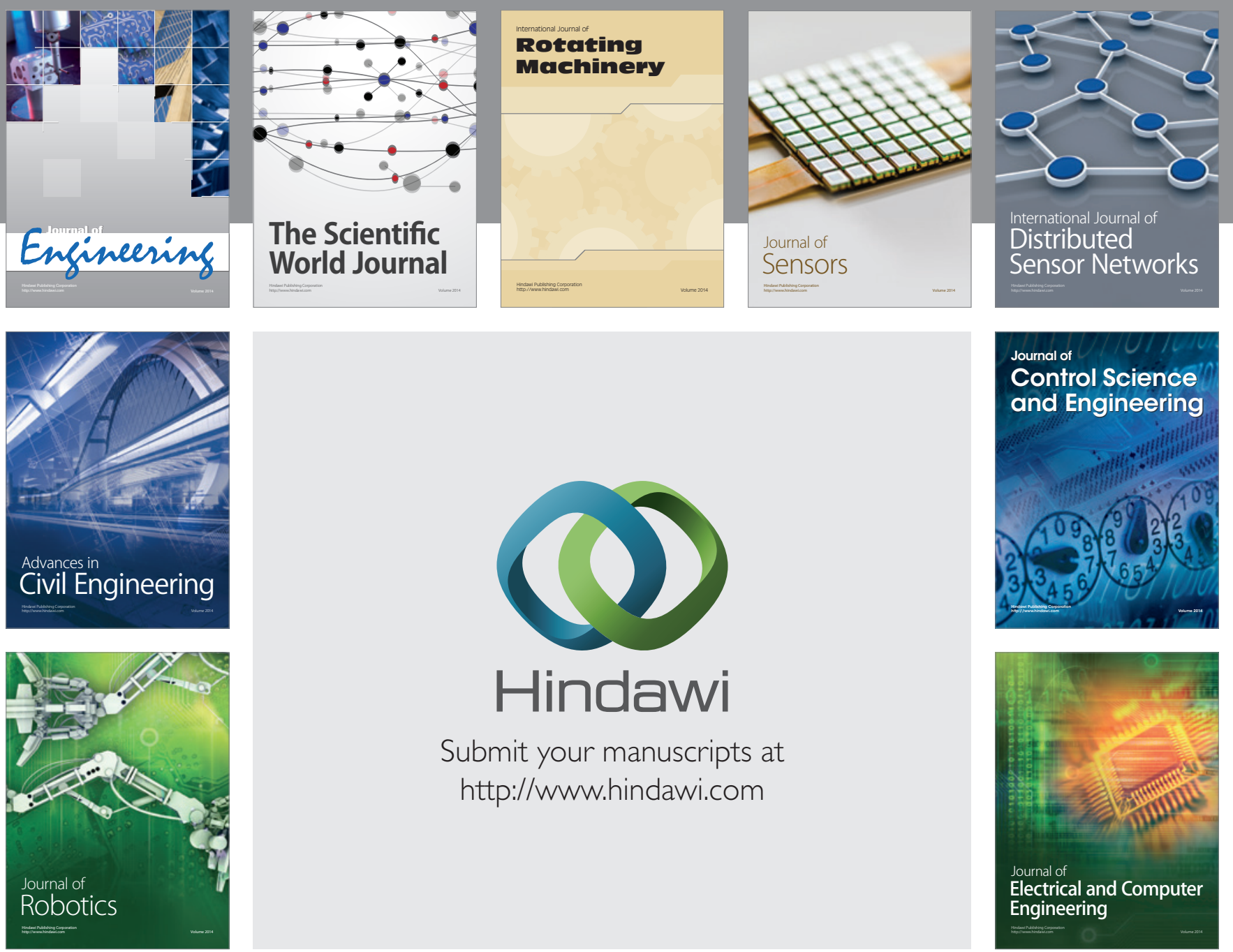

Submit your manuscripts at

http://www.hindawi.com
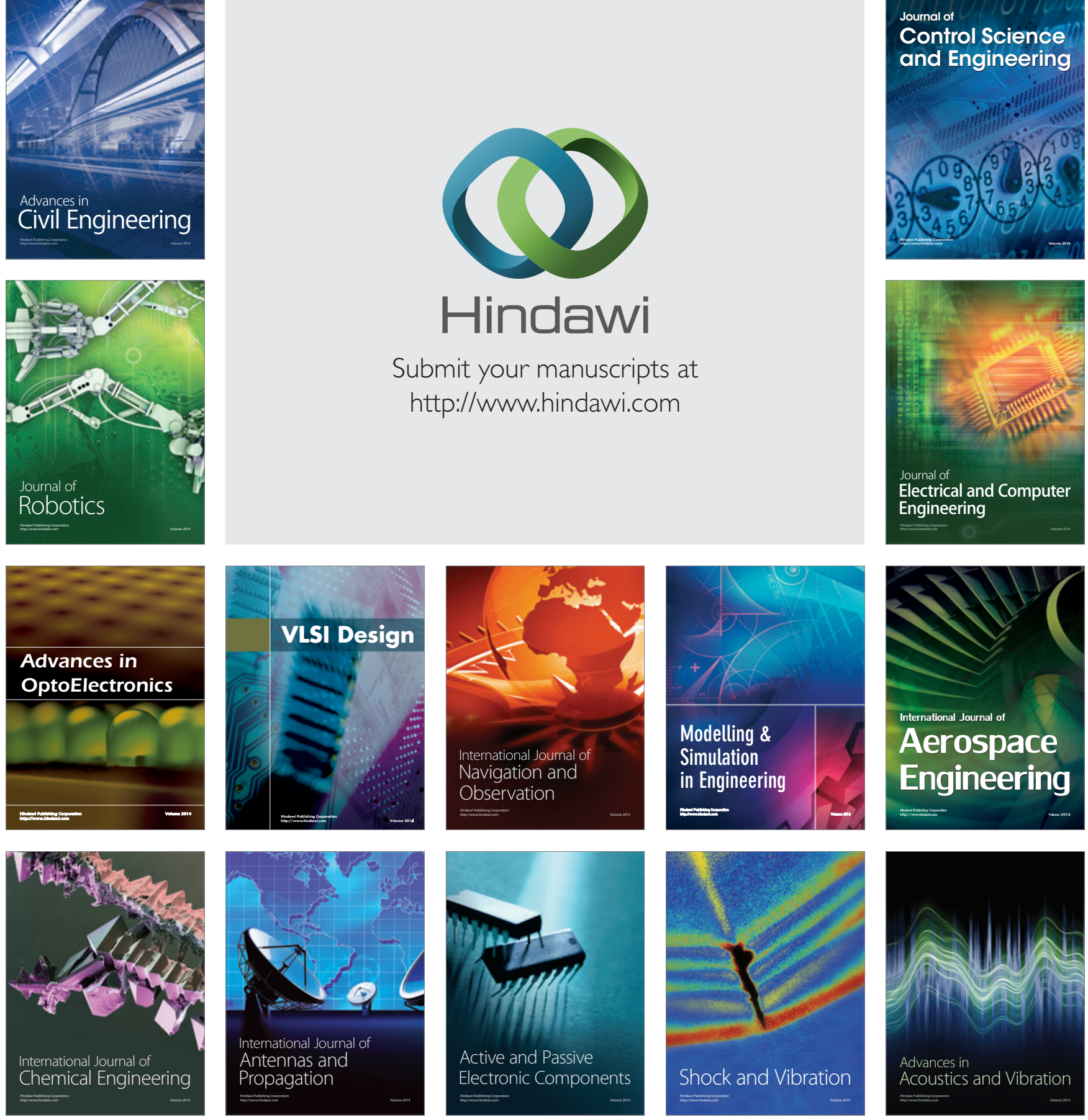